\title{
Investigation of the Motivation of Nurses Working in a Mental Health and Psychiatry Hospital to Approach or Avoid Emotion Inducing Situations in Terms of Some Parameters
}

\author{
Sinan Vatansever ${ }^{1}(\underline{I D})$, Oya Sevcan Orak ${ }^{2(\underline{I D})}$ \\ ${ }^{1}$ Department of Mental Health and Disease Nursing, Health Sciences Institute, Ondokuz Mayis University, Samsun, Turkey, \\ ${ }^{2}$ Department of Psychiatric Nursing, Health Sciences Faculty, Ondokuz Mayıs University, Samsun, Turkey,
}

Copyright@ Author(s) - Available online at https://dergipark.org.tr/en/pub/mbsjohs

Content of this journal is licensed under a Creative Commons Attribution-NonCommercial 4.0 International License,

Received: 22 October 2020, Accepted: 23 February 2021, Published online: 30 April 2021

(C) Ordu University Institute of Health Sciences, Turkey, 2021

\begin{abstract}
Objective: This study aims to investigate the motivation of nurses, who are working in a mental health and illness hospital, to approach or avoid emotion inducing situations in terms of some parameters.

Methods: This descriptive study was conducted with 101 nurses who worked in Samsun Mental Health and Illness Hospital between June 2017 and July 2017 and met the inclusion criteria. In the study, the "Demographic Information Sheet" and "Need for Affect Scale" were used as a data collection tool.

Results: The nurses who thought that they were capable of recognizing their feelings had a low score from the avoidance sub-scale $(\mathrm{p}<0.05)$. The nurses who thought that they were capable of expressing their feelings had a high score from the approach sub-scale but a low score from the avoidance sub-scale $(p<0.05)$. The nurses, who expressed that they partially abstain from participating in emotionally intense environments in their social lives, had a higher score from the avoidance sub-scale $(\mathrm{p}<0.05)$.

Conclusion: It was concluded that for the nurses working in the mental health and illness hospital where the study was conducted, the parameter of thinking to be capable of expressing their feelings affected the motivation to approach emotion-inducing situations; while the parameters of thinking to be capable of recognizing feelings, of abstaining from participating in emotionally intense environments in social life, of thinking that individuals with mental illness are dangerous and having difficulty when working with them affected the avoidance motivation.
\end{abstract}

Key words: Need for Affect, Nurse, Psychiatric Nurse.

Suggested Citation: Vatansever S, Orak O S. Investigation of the motivation of nurses working in a mental health and psychiatry hospital to approach or avoid emotion inducing situations in terms of some parameters.Mid Blac Sea Journal of Health Sci, 2021; $7(1): 15-23$

\section{Address for correspondence/reprints:}

Oya Sevcan Orak,

Telephone number: +90 (362)3121919-6352,

E-mail: oysev@hotmail.com

\section{Introduction}

Emotion is "fluctuations in a person's inner world with the effect of thoughts" (1). Emotion is the "feeling" aspect of consciousness and is characterized by three elements: These include certain physical arousal, certain behavior that reveals the emotion to the outside world, and an inner awareness of feelings (2). Emotions send fast and powerful physical messages, enabling respond to the environment. 
Thus, they allow us to communicate with the environment, whether willingly or unwillingly (3). According to Maio and Esses (2001), emotions often arise from some specific cognitive states, and cognitive tasks often involve some emotion (4).

People have differences in participating in and abstaining from emotion-inducing activities. This is directly explained by their need for affect. The need for affect is defined as the general motivation level of people for participating in or abstaining from situations and activities containing various emotions for themselves and others (4). Emotional approach and emotional avoidance originate from our different experiences. People often have higher motivation towards emotional approach then emotional avoidance. Because the approach motivation provides higher intrinsic satisfaction (5). In other words, since having emotional experience provides intrinsic motivation in at least one level as well as emotions promote motivational behavior and guide justifications, the motivation to approach emotions becomes high (4). Individuals who like having emotional experiences further tend to have extreme opinions regarding controversial topics and to discuss with others about them, because extreme opinions and discussions give people the opportunity to experience strong emotions. This makes individuals with a high need for affect more open and willing to learn new and different new topics. Individuals with high need for affect want to engage in emotionally intense activities such as watching theatre, reading a novel or poem or watching a horror movie, while those with a low need for affect tend to abstain from such activities. Such behaviors and tendencies are associated with the need for affect, they are also associated with personal characteristics, which are one of the main determinants of such behaviors (6).

Nursing is a profession that requires working with healthy individuals/patients and their families mostly in emotionally charged environments and activities (7). Especially nurses working in psychiatric clinics more often encounter with emotionally charged environments since they provide care for individuals with a mental disorder (8). Since nurses providing care for individuals with a mental disorder are the group that spends the most time with the patient, they are the manager, coordinator as well as user of the environment when creating the therapeutic environment. Nurses working in psychiatric clinics are also expected to use therapeutic communication techniques when communicating with patients (9). For a therapeutic patient-nurse communication, the nurse should be highly motivated to approach the emotionally charged relationship with the patient (4) using several therapeutic techniques such as expressing observations about patient-nurse communication, encouraging for conversation, being acquiescent, exploring, concentrating on emotions and reflecting emotions (9). It is thought that many parameters have effect on the motivation of nurses to approach and avoid emotionally charged environments. Nurses are adversely affected by various situations such as the chronic and long-term nature of the mental illness, having difficulties with communication and relationships with the patient and his/her relatives, working with aggressive patients, very stressed patients (10). On the other hand, the parameters related to the working environment of nurses are also important. A study found that $72.2 \%$ of nurses worked at both day and night, $38.9 \%$ of them were subjected to physical violence, and $85.7 \%$ of those being subjected to physical violence worked in psychiatric clinics (11). A study performed by Dil and Aykanat (12) with students taking mental health and illness nursing course found that the "motivation to approach emotions" was significantly increased and positive changes occurred in the "motivation to avoid emotions" after taking the course.

No study was found in the literature, where the motivation of nurses working in psychiatric clinics to approach and avoid emotionally charged environments was investigated in terms of personal and professional parameters. This study aims to investigate the motivation of nurses, who are working in a mental health and illness hospital, to approach or avoid emotion-inducing situations in terms of some parameters.

In the study, the following questions were sought:

-What are the parameters affecting the motivation of nurses working in a mental health and illness hospital to approach emotionally charged environments?

-What are the parameters affecting the motivation of nurses working in a mental health and illness hospital to avoid emotionally charged environments?

\section{Methods}

\section{Study Design and Setting}

This study is descriptive. The study universe consisted of 119 nurses who worked in Mental Health and Illness Hospital between June 2017 and July 2017; the study sample consisted of 101 nurses who met the inclusion criteria. The sample was determined based on the study performed by Süt in 2011 (13). Before starting the study, the sample size was determined by power analysis, and it was found that at least 101 nurses should be included in the study for 
a $95 \%$ confidence interval and an $89 \%$ power. The nurses who have permanently worked in the Mental Health and Illness Hospital and volunteered to participate in the study were included in the study.

\section{Ethical issues}

To conduct the study, permission was obtained from Mental Health and Illness Hospital and affiliated institutions (Number: 61646299/044; Date: 26.10.2017); ethics committee approval was obtained from the Clinical Researches Ethics Committee of the university in the city where the study was conducted (Number: B.30B2BDM.0.20.08/1029; Date: 23.06.2017), and permission to use scale was obtained from Prof. Dr. Veli Duyan who prepared the Turkish Version of the "Need for Affect Scale" used in the study. The nurses were informed about the study, and their written and verbal consents were obtained.

\section{Instruments}

Nurse Demographic Information Sheet: This sheet that was prepared by the researcher based on the literature $(4,12,14,15)$ consists of a total of 13 questions. This sheet contains 5 questions on sociodemographic characteristics of nurses, 4 questions on their emotional characteristics, and 4 questions on emotional characteristics for working with individuals with mental illness.

Need for Affect Scale (NAS): It was developed by Maio and Esses in 2001 to evaluate the needs for people (4). The Turkish version of this scale was prepared by Duyan et al. in 2011 (14). The Need for Affect Scale (NAS) is a self-measure scale to evaluate the motivation of individuals to approach and avoid emotional environments. The scale has a total of 26 items: 13 in the emotional approach sub-scale and 13 in the emotional avoidance sub-scale. The individuals are asked for expressing their opinions about the items on the 7-point scale, ranging from "strongly disagree -3 " to "strongly agree +3 ". The score from each subscale ranges from -39 to +39 . The overall score from the need for affect scale ranges from -78 to +78 . A high score from the inventory means that the participant has a high motivation to approach emotions, while a low score means that the participant has low motivation to approach emotions. The reliability analysis of the scale used in the study showed that the approach sub-scale is reliable, and the avoidance sub-scale is highly reliable. In the study, the Cronbach's alpha coefficient of the Need for Affect Scale was found 0.751

\section{Statistical analysis}

The data were evaluated using SPSS 21.00 program. The statistical evaluation was performed based on descriptive statistics, independent t-test, ANOVA, Pearson correlation analysis. In the study, the significance level was taken as $\mathrm{p}<0.05$.

\section{Results}

The demographic information of the nurses included in the study is given in Table 1. Of the nurses participating in the study, $70.3 \%$ were women, $77.2 \%$ were married and $71.3 \%$ had a bachelor's degree. $70.3 \%$ of the nurses worked in inpatient ward, and $84.2 \%$ received education on approach to individuals with mental illness (Table 1).

The distribution of the emotional characteristics of the nurses is given in Table 2. $39.6 \%$ of the nurses included in the study stated that they receive support from their colleagues when they are emotionally charged. $48.5 \%$ of the nurses stated that they are capable of recognizing their emotions, $47.5 \%$ stated that they are partially capable of expressing their emotions, and $52.5 \%$ stated that they partially abstain from participating in emotionally intense environments in their social lives (Table 2).

The distribution of the emotional characteristics of the participating nurses regarding working with individuals with mental illness is given in Table 3. $34.7 \%$ of the nurses answered the question "What do you have emotional difficulties with when working with individuals with mental illness?" as "patient behaviors", while $28.7 \%$ of the nurses answered the question "What emotion do you experience most often when working with individuals with mental illness?" as "all emotions", and $28.7 \%$ of them answered the same question as "sadness". 55.4\% of the nurses answered the questions "Do you think that you are capable of managing various emotional situations seen in individuals with mental illness?" and "Do you think that individuals with mental illness are dangerous?" as "partially" (Table 3 ). 
Table 1. Distribution of nurses by their demographic characteristics Characteristics

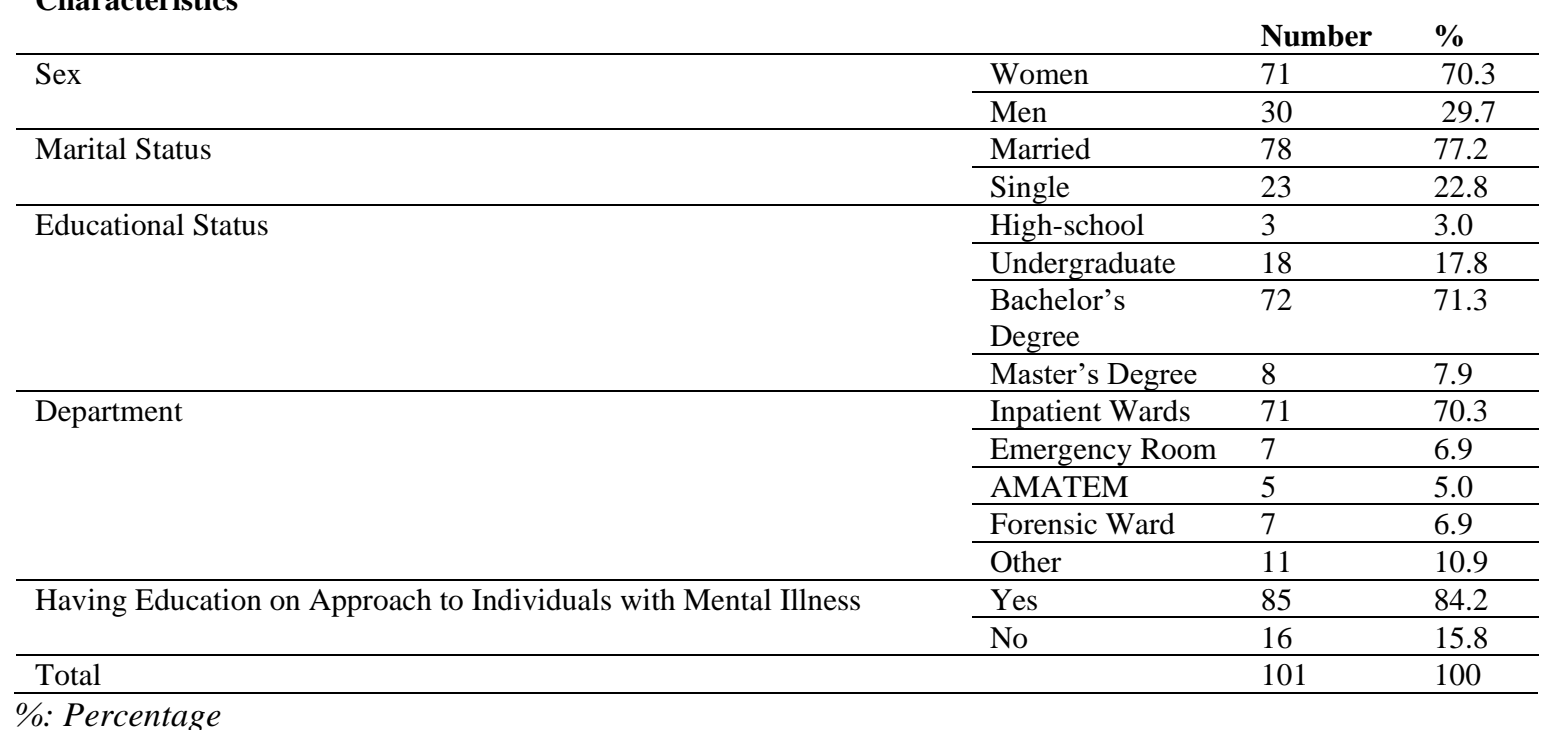

Table 2. Distribution of emotional characteristics of nurses

\begin{tabular}{|c|c|c|c|}
\hline Characteristics & & Number & $\%$ \\
\hline \multirow{5}{*}{$\begin{array}{l}\text { Persons from Whom Support is Received When Being } \\
\text { Emotionally Charged }\end{array}$} & Family & 30 & 29.7 \\
\hline & Relative & 5 & 5.0 \\
\hline & Friend & 40 & 39.6 \\
\hline & Mental Health Specialist & 18 & 17.8 \\
\hline & Other & 8 & 7.9 \\
\hline \multirow[t]{2}{*}{ Thinking to be Capable of Recognizing Emotions } & Yes & 49 & 48.5 \\
\hline & Partially & 47 & 46.5 \\
\hline \multirow[t]{3}{*}{ Thinking to be Capable of Expressing Emotions } & Yes & 43 & 42.6 \\
\hline & No & 10 & 9.9 \\
\hline & Partially & 48 & 47.5 \\
\hline $\begin{array}{l}\text { Abstaining from Participating in Emotionally Intense } \\
\text { Environments in Social Life }\end{array}$ & Yes & 18 & 17.8 \\
\hline
\end{tabular}

Table 3. Distribution of the emotional characteristics of the nurses regarding working with individuals with mental illness

\begin{tabular}{|c|c|c|c|}
\hline \multirow{5}{*}{$\begin{array}{l}\text { Characteristics } \\
\text { Issues That They Have Emotional Difficulties When Working } \\
\text { with Individuals with Mental Illness }\end{array}$} & & Number & $\%$ \\
\hline & Patient Behaviors & 35 & 34.7 \\
\hline & Histories of Patients & 31 & 30.7 \\
\hline & Emotional Burdens of Patients & 31 & 30.7 \\
\hline & Other Characteristics of Patients & 4 & 4.0 \\
\hline \multirow{8}{*}{$\begin{array}{l}\text { Emotion Most Often Experienced When Working with } \\
\text { Individuals with Mental Illness }\end{array}$} & Anger & 6 & 5.9 \\
\hline & Fear & 10 & 9.9 \\
\hline & Sadness & 29 & 28.7 \\
\hline & Pity & 13 & 12.9 \\
\hline & Shame & 4 & 4.0 \\
\hline & Discomfort & 7 & 6.9 \\
\hline & All Emotions & 29 & 28.7 \\
\hline & Other & 3 & 3.0 \\
\hline \multirow{3}{*}{$\begin{array}{l}\text { Thinking to be Capable of Managing Various Emotional } \\
\text { Situations Seen in Individuals with Mental Illness }\end{array}$} & Yes & 25 & 24.8 \\
\hline & No & 20 & 19.8 \\
\hline & Partially & 56 & 55.4 \\
\hline \multirow[t]{3}{*}{ Thinking that Individuals with Mental Illness are Dangerous } & Yes & 21 & 20.8 \\
\hline & No & 24 & 23.8 \\
\hline & Partially & 56 & 55.4 \\
\hline Total & & 101 & 100 \\
\hline
\end{tabular}


The average score of the nurses from the "Approach" sub-scale of the NAS was $5.52 \pm 8.77$; the average score of them from the "Avoidance" subscale was $-7.54 \pm 13.36$.

The scores of the nurses from the NAS approach and avoidance sub-scales by their emotional characteristics were examined and given in Table 4. No statistically significant difference was found between the scores of the nurses from the NAS approach and avoidance sub-scales by persons from whom they receive support when they are emotionally charged $(p>0.05)$. The nurses, who thought that they were capable of recognizing emotions, received significantly low scores from the avoidance sub-scale $(\mathrm{p}<0.05)$; no statistically significant difference was found between the scores from the approach sub-scale in terms of this parameter $(p>0.05)$. The nurses, who thought that they were capable of expressing their emotions, received significantly low scores from the avoidance sub-scale $(p<0.05) ;$ no statistically significant difference was found between the scores from the approach sub-scale $(\mathrm{p}>0.05)$. The nurses, who stated that they abstained from participating in emotionally intense environments in their social lives, received significantly high scores from the avoidance subscale $(\mathrm{p}<0.05)$; no statistically significant difference was found between the scores from the approach subscale in terms of this parameter ( $p>0.05$; Table 4).

In the study, the distribution of the scores of the nurses from the NAS approach and avoidance subscales in terms of some parameters regarding working with individuals with mental illness was examined and given in Table 5. It was found that the nurses, who answered the question "What do you have emotional difficulties with when working with individuals with mental illness?" as "Emotional burdens of patients" and the question "Do you think that individuals with mental illness are dangerous?" as "Yes", had significantly higher scores from the avoidance sub-scale $(\mathrm{p}<0.05)$. No statistically significant difference was found between the scores from the NAS approach and avoidance sub-scales in terms of other parameters ( $p>0.05$; Table 5$)$.

Table 4. Distribution of the scores of nurses from NAS approach and avoidance sub-scales by emotional characteristics

\begin{tabular}{|c|c|c|c|c|c|}
\hline & & Approach & & Avoidance & \\
\hline Characteristics & & Avg.土 SD & Test and p & Avg.土 SD & Test and p \\
\hline \multirow{5}{*}{$\begin{array}{l}\text { Persons From Whom Support is } \\
\text { Received When Being Emotionally } \\
\text { Charged }\end{array}$} & Family & $6.86 \pm 6.39$ & \multirow{5}{*}{$\begin{array}{l}F=0,500 \\
p=0.776\end{array}$} & $-8.86 \pm 14.39$ & \multirow{5}{*}{$\begin{array}{l}F=0.971 \\
p=0.440\end{array}$} \\
\hline & Relative & $3.2 \pm 12.04$ & & $-3.2 \pm 17.23$ & \\
\hline & Friend & $5.58 \pm 8.09$ & & $-9.28 \pm 13.09$ & \\
\hline & $\begin{array}{l}\text { Mental Health } \\
\text { Specialist }\end{array}$ & $8.29 \pm 7.12$ & & $-3.66 \pm 10.85$ & \\
\hline & Other Persons & $5.62 \pm 13.5$ & & $-3.62 \pm 15.84$ & \\
\hline \multirow{3}{*}{$\begin{array}{l}\text { Thinking to be Capable of } \\
\text { Recognizing Emotions }\end{array}$} & Yes & $9.80 \pm 6.83$ & \multirow[b]{3}{*}{$\begin{array}{l}\mathrm{F}=0.955 \\
\mathrm{p}=0.418\end{array}$} & $-14.30 \pm 11.60$ & \\
\hline & No & $4.13 \pm 8.90$ & & $6.80 \pm 6.97$ & \\
\hline & Partially & $6.39 \pm 9.00$ & & $-2.74 \pm 12.39$ & $\begin{array}{l}\mathrm{F}=9.724 \\
* \mathbf{p}<\mathbf{0 . 0 0 1}\end{array}$ \\
\hline \multirow{3}{*}{$\begin{array}{l}\text { Thinking to be Capable of } \\
\text { Expressing Emotions }\end{array}$} & Yes & $7.47 \pm 8.36$ & \multirow{3}{*}{$\begin{array}{l}F=2.518 \\
p=0.086\end{array}$} & $-12.48 \pm 13.30$ & \\
\hline & $\mathrm{No}$ & $0.62 \pm 10.23$ & & $-12.00 \pm 13.59$ & \\
\hline & Partially & $4.66 \pm 8.68$ & & $-2.81 \pm 11.83$ & $\begin{array}{l}\mathrm{F}=7.021 \\
* \mathrm{p}=\mathbf{0 . 0 0 1}\end{array}$ \\
\hline \multirow{3}{*}{$\begin{array}{l}\text { Abstaining from Participating in } \\
\text { Emotionally Intense Environments } \\
\text { in Social Life }\end{array}$} & Yes & $5.10 \pm 9.77$ & \multirow{3}{*}{$\begin{array}{l}F=0,290 \\
p=0.749\end{array}$} & $-8.81 \pm 12.38$ & \multirow{3}{*}{$\begin{array}{l}F=6,114 \\
* \mathbf{p}=\mathbf{0 , 0 0 3}\end{array}$} \\
\hline & No & $7.12 \pm 8.46$ & & $-13.56 \pm 13.46$ & \\
\hline & Partially & $5.68 \pm 7.92$ & & $-3.41 \pm 12.40$ & \\
\hline
\end{tabular}

F: ANOVA, ${ }^{*} p<0.05$ 
Table 5. The Distribution of the scores of the nurses from the NAS approach and avoidance sub-scales in terms of some parameters regarding working with individuals with mental illness

\begin{tabular}{|c|c|c|c|c|c|}
\hline & & Approach & & Avoidance & \\
\hline Characteristics & & Avg. \pm SD & Test and $p$ & Avg.土 SD & $\begin{array}{l}\text { Test and } \\
\text { p }\end{array}$ \\
\hline \multirow{4}{*}{$\begin{array}{l}\text { Issues That They Have Emotional } \\
\text { Difficulties When Working with } \\
\text { Individuals with Mental Illness }\end{array}$} & Patient Behaviors & $5.00 \pm 9.66$ & \multirow{4}{*}{$\mathrm{F}=1,152$} & $-14.06 \pm 12.15$ & \multirow{4}{*}{$F=5,659$} \\
\hline & Histories of Patients & $7.00 \pm 6.71$ & & $-7.36 \pm 13.87$ & \\
\hline & $\begin{array}{l}\text { Emotional Burdens of } \\
\text { Patients }\end{array}$ & $3.72 \pm 9.75$ & & $-0.72 \pm 11.67$ & \\
\hline & $\begin{array}{l}\text { Other characteristics } \\
\text { of patients }\end{array}$ & $10.50 \pm 5.00$ & & $-9.00 \pm 10.86$ & \\
\hline \multirow{8}{*}{$\begin{array}{l}\text { Emotion Most Often Experienced } \\
\text { When Working with Individuals } \\
\text { with Mental Illness }\end{array}$} & Anger & $3.50 \pm 9.95$ & \multirow{8}{*}{$\mathrm{F}=0,590$} & $-2.00 \pm 14.46$ & \multirow{8}{*}{$\mathrm{F}=1,628$} \\
\hline & Fear & $5.44 \pm 7.33$ & & $-10.22 \pm 11.15$ & \\
\hline & Sadness & $5.36 \pm 11.61$ & & $-11.32 \pm 13.79$ & \\
\hline & Pity & $2.07 \pm 8.33$ & & $-7.15 \pm 10.66$ & \\
\hline & Shame & $7.75 \pm 3.40$ & & $3.00 \pm 9.55$ & \\
\hline & Discomfort & $5.00 \pm 7.64$ & & $-3.66 \pm 14.09$ & \\
\hline & All emotions & $7.44 \pm 6.40$ & & $8.33 \pm 10.40$ & \\
\hline & Other & $8.33 \pm 15.50$ & & $-6.75 \pm 13.25$ & \\
\hline \multirow{3}{*}{$\begin{array}{l}\text { Thinking to be Capable of } \\
\text { Managing Various Emotional } \\
\text { Situations Seen in Individuals } \\
\text { with Mental Illness }\end{array}$} & Yes & $8.45 \pm 7.02$ & \multirow{3}{*}{$\mathrm{F}=1,600$} & $-12.95 \pm 11.84$ & \multirow{3}{*}{$\mathrm{F}=1,636$} \\
\hline & No & $3.73 \pm 9.85$ & & $-5.73 \pm 13.49$ & \\
\hline & Partially & $5.18 \pm 8.94$ & & $-6.44 \pm 13.39$ & \\
\hline \multirow{3}{*}{$\begin{array}{l}\text { Thinking that Individuals with } \\
\text { Mental Illness are Dangerous }\end{array}$} & Yes & $3.40 \pm 10.68$ & \multirow{3}{*}{$\begin{array}{l}\mathrm{F}=0,955 \\
\mathrm{p}=0.389\end{array}$} & $-0.08 \pm 10.970$ & \multirow{3}{*}{$\begin{array}{l}\mathrm{F}=0,389 \\
* \mathbf{p}=\mathbf{0 , 0 0 6}\end{array}$} \\
\hline & No & $7.08 \pm 5.78$ & & $-11.60 \pm 12.11$ & \\
\hline & Partially & $5.64 \pm 9.05$ & & $-9.18 \pm 13.69$ & \\
\hline
\end{tabular}

\section{Discussion}

The results obtained from the study conducted to investigate the motivations of nurses, who work in a mental health and illness hospital, to approach and avoid emotion-inducing situations in terms of some parameters were discussed in this section.

When the scores of nurses, who work in mental health hospital, from the NAS sub-scales were examined, it was found that the average score from the "Approach" sub-scale was 5.52 \pm 8.77 , and the average score from the "Avoidance" sub-scale was $7.54 \pm 13.36$. When these values were evaluated in terms of the lowest and highest scores from the scale, it was found that the approach motivation was partially higher, while the avoidance motivation was partially lower. In a study conducted with students taking Mental Health and Illnesses Nursing course, the average pre-test score from the NAS emotional approach sub-scale was found $16.52 \pm 8.9$, and the average score from the NAS emotional avoidance sub-scale was found $-7.00 \pm 12.33$ (15). In another study investigating the effect of the "Mental Health and Illnesses Nursing" course on the emotional approach and avoidance motivation levels of students, the average pre-test score from the NAS "emotional approach" sub-scale was found $15.62 \pm 9.89$, while the average post-test score was found $27.17 \pm 10.91$. In the same study, the average pre-test score from the "emotional avoidance" subscale was found $9.77 \pm 11.32$ and the average post-test score was found $8.40 \pm 12.65$ (12). A study conducted with pediatric nurses found that the average approach sub-size score of nurses was $7.31 \pm 12.62$ and the average avoidance sub-size score was $-8.85 \pm 11.50$ (16). In another study with university students, the average score from the approach sub-scale was found $8.70 \pm 12, .03$, while the average score from the avoidance sub-scale was found $-4.18 \pm 12.42$ (17). When the study results were compared with the literature, it can be said that the motivation of the nurses to approach emotional situations was low. Some study results showed that the avoidance motivation was lower.

It was found that the nurses in the study, who thought that they were capable of recognizing their emotions, had low motivation to avoid emotional situations $(\mathrm{p}<0.05$; Table 4$)$; although they had high approach motivation, the difference was not statistically significant $(p>0.05$; Table 4$)$. It was found that the nurses, who thought that they were capable of expressing their emotions, had low motivation to avoid emotional situations $(p<0.05$; Table 4); although they had high approach motivation, the difference was not statistically 
significant ( $>0.05$; Table 4). It was reported that nurses, who can recognize and manage their feelings, empathize, direct their relationship and realize themselves, can protect the mental health of themselves as well as thus provide better care to healthy individuals/patients, contributing to the protection of mental health of the society $(18,19)$. In the literature, it was reported that nurses, who are open to understanding their own emotions, can know how to respond to patient and how to be perceived; and a nurse can understand the emotions of others only if he/she can recognize their own emotions and thoughts and control and manage them (20). Rime and Zech (21) reported that people need to express their emotional experiences and mutual communication has an important role in meeting this need. Studies show that people should express their emotional experiences and mutual communication has an important role in meeting this need $(12,21)$. A study by Dil and Aykanat (12) found that after Mental Health and Illnesses Nursing training and practices, the emotional approach behaviors of students improved and the emotional avoidance behaviors reduced, although not statistically significant. Another study by Âsik and Albayrak (15) found that Mental Health and Illnesses Nursing course improved the emotional awareness of students and was effective in emotional needs such as "emotional approach" and "emotional avoidance". In the study, it was found that $84.2 \%$ of nurses received training on approach to individuals with mental illness. The fact that $71.3 \%$ of the nurses in the study had a bachelor's degree is important for them to have psychiatric nursing knowledge and skills. It is thought that these characteristics of the nurses in the study play a role in the fact that they have low motivation to avoid emotional situations.

The study found that the nurses, who expressed that they abstain from participating in emotionally intense environments in their social lives, had high avoidance motivation ( $\mathrm{p}<0.05$; Table 4). According to Maio and Esses (4), when people have an emotional experience, they need to understand the emotions of both themselves and others. This leads to the motivation to approach or avoid emotions. If people are discomfort about the emotions they experience, they do not attempt to experience them and to understand the emotions of others. People may have differences in participating in and abstaining from emotionally intense activities. This is directly related to their need for emotion. Since the majority of the nurses in the study received undergraduate education, they were equipped with both professional and life skills. On the other hand, the majority of the nurses stated that they received specific education on approach to individuals with mental illness. The studies with students receiving mental health and illness nursing course showed that the course affects the emotional needs $(12,15)$. It was also reported that the "Self-Recognition and Assertiveness" course given in nursing undergraduate education improved assertiveness skills including the ability to show emotions easily (22). It is thought that all these factors affect the study results.

It was found that the nurses, who answered the question "What do you have emotional difficulties with when working with individuals with mental illness?" as "Emotional Burdens of Patients" had a high avoidance motivation ( $\mathrm{p}<0.05$; Table 5$)$. Nurses are one of the healthcare professionals who most often communicate with individuals with a mental problem during the hospitalization period (23). The need for approach to emotions increases participation in emotionally intense activities and ensures to show a tendency to experience emotions (4). However, it is thought that there are factors affecting the motivation to approach emotionally charged situations because the place where this need is to be met is a hospital environment. Nursing knowledge and skills, which need to be free from personal curiosity and to interact with the individual they care for, with the aim of help and with their authentic existence, must also be included in the process. A study reported that student nurses have experienced ambivalence about the competence of their skills in helping with the psychiatric patient (24). The fact that the time allocated for theory and practice during the education process is insufficient also plays a role in nurses' failure to overcome negative attitudes towards mental illnesses (25). Another factor is the belief systems towards individuals with mental illness. It was found that the nurses answered the question "Do you think that individuals with mental illness are dangerous?" as "Yes" had a high avoidance motivation $(\mathrm{p}<0.05$; Table 5). Believing that individuals with mental illness are dangerous prepares the ground for attributing negative emotions towards such individuals. To cope with these negative emotions, social stigmatizing behaviors arise. One of them is avoidance (26). "Sadness" is one of the emotions which the nurses in the study most often experienced when working with individuals with mental illness. It is thought that the belief system towards psychology patient/illness played a role in the avoidance motivation of the nurses, who stated that they had difficulties with the emotional burdens of patients when working with individuals with mental illness and thought that such individuals are dangerous. 


\section{Limitations of the Study}

This research it was conducted among working nurses at a mental health and diseases hospital in Turkey. The results obtained from the research can be generalized to this hospital.

\section{Conclusion}

The results and recommendations obtained from the study conducted to investigate the motivations of nurses, who work in a mental health and illness hospital, to approach and avoid emotion-inducing situations in terms of some parameters were given in this section.

The results of the study are as follows:

- The motivation of the nurses to approach emotional situations was above medium level, while their avoidance motivation was below medium level,

- The nurses who thought that they were capable of recognizing their emotions had a significantly low score from the avoidance sub-scale,

- The nurses who thought that they were capable of expressing their emotions had a significantly low score from the avoidance sub-scale,

- The nurses, who expressed that they abstain from participating in emotionally intense environments in their social lives, had a significantly high score from the avoidance sub-scale,

- The nurses, who stated that they had difficulties with the emotional burdens of patients when working with individuals with mental illness, had significantly high scores from the avoidance subscale,

- The nurses, who thought that individuals with mental illness were dangerous, had significantly high scores from the avoidance sub-scale.

Based on the study results, it is recommended;

- to increase the number of courses to be conducted by the "Department of Psychiatric Nursing" in the curriculum of the Nursing Undergraduate Programs of universities,

- to make arrangements and improvements to reach the targeted skills in Mental Health and Illnesses Nursing courses in the Nursing Undergraduate Program,

- to create an education program to increase the motivation of nurses working in psychiatric clinics to approach emotional situations,

- to perform intervention studies in this regard.
Ethics Committee Approval: Ethics committee approval for this study was received from the Ondokuz Mayıs University Clinical Research Ethics Committee (ethics committee date and number: 23.06.2017; B.30.2.ODM.0.20.08 / 1029).

Peer-review: Externally peer-reviewed.

\section{Author Contributions:}

Concept: O.S.O, Design: O.S.O, S.V, Literature Search: O.S.O, S.V, Data Collection and Processing: S.V. Analysis or Interpretation: O.S.O, Writing: O.S.O, S.V.

Conflict of Interest: No conflict of interest was declared by the author.

Financial Disclosure: The author declared that this study hasn't received no financial support.

\section{References}

1. Elmacioglu T. Feeling Better. Yediveren Publications Bahcelievler, Istanbul. 2012;3.

2. Ciccarelli, SK, Noland, White J. Psychology An Exploration. Sahin DN. Translation Editor. Nobel Academic Publishing, Ankara. 2018; 324-363.

3. Furnham A. 50 Psychology ideas you really should know. Agiryuruyen S. Translation Editor. Domingo, İstanbul. 2018; 60-64.

4. Maio GR, Esses VM. The need for affect: individual differences in the motivation to approach or avoid emotions. J Pers 2001; 69(4): 583-615.

5. Schwarz N. Feelings As information: informational and motivational functions of affective states. In: R. M. Sorrentino, \& E. T. Higgins (Ed), Handbook of motivation and cognition: foundations of social behavior. Guilford Press, New York. 1990; 527561.

6. Appel M, Gnambs T, Maio GR. A short measure of the need for affect. Journal of Personality Assessment 2012; 94(4): 418-426.

7. Lankau A, Krajewska-Kułak E, Jankowiak B, Baranowska A, Bejda G. Effect of nurses' religious beliefs on their empathy and life satisfaction. Progress in Health Sciences 2017; 7(2): 18-25.

8. Toru A. Stress and Burnout. Industrial and organizational psychology. Turkish Psychologists Association, İstanbul. 1997; 43-45.

9. Cam O, Dulgerler S. Basic therapeutic tools in mental health and disease nursing: Environment and Communication. In: Cam O, Engin E, Editor. The art of mental health and disease nursing care. Istanbul Medical Bookstore, İstanbul. 2014; 157 78.

10. Sinat O, Kutlu Y. Burnout in nurses working in psychiatry clinics. İstanbul University Florence Nightingale Nursing Journal 2009; 17 ( 3): 174-183. 
11. Coskun S, Sarlak K, Tastan H. An investigation on the level of learned resourcefulness and professgonal quality of life of psychiatric nurses: A comparative study. Gumushane University Journal of Health Sciences 2015; 4 (1): 84-100.

12. Dil S, Aykanat B. The effects of a mental health and psychiatric nursing course on the approach and avoidance motivation levels of nursing students to emotional situations. Journal of Psychiatric Nursing 2013; 4 (3): 125-130.

13. Sut N. Sample size determination and power analysis in clinical trials. Read Journal 2011; 3(12): 29-33.

14. Duyan V, Ucar ME, Kalafat T. Adaptating the need for affect scale to Turkish culture and its psychometric qualities. Education and Science 2011; 36, 30-116.

15. Âsik E, Albayrak S. Levels of approachavoidance towards emotional situations of student nurses taking and not taking the mental health and psychiatric diseases nursing course and their perceptions of problem-solving. Journal of Health Sciences of Kocaeli University 2016; 2(1): 39-43.

16. Kurt Sezer H, Geckil E. Investigation of pediatric nurses' emotional needs and their views on spirituality and spiritual care. J H U Faculty of Nursing 2020; 7(2): 167-174.

17. Yilmaz T, Top E, Akil M. Levels of approaching and avoiding emotional situations of the students studying in the faculties of sport sciences. Journal of Physical Education and Sport 2016;16 (1): 258.

18. Bellack JP. Emotional intelligence: A missing ingredient? Journal of Nursing Education 1999; 38(1):3-4.

19. Akerjordet K, Severinsson E. Emotional intelligence in mental health nurses talking about practice. İnt J Ment Health Nurs 2004; 3: 70-164.

20. Ozcan A. Nurse-Patient relationship and communication. Sistem Offset, Ankara. 2006; 4-31.

21. Rime B, Zech E. The Social sharing of emotion: interpersonal and collective dimensions. Boletin de Psicologia 2001; 97-108.

22. Kelleci M, Avci D, Ata EE, Dogan S, Ata E. The effect of self-knowledge and assertiveness course on the assertiveness level of nursing students. Journal of Anatolia Nursing and Health Sciences 2011; 14: 46-51.

23. Arkan B, Bademli K, Cetinkaya Duman Z. Attitudes of health professionals towards mental disorders: Studies in Turkey during the last decade. Current Approaches in Psychiatry 2011; 3(2): 217.
24. Ketola J, Stein JV. Psychiatric clinical course strengthens the student-patient relationships of baccalaureate nursing students. Journal of Psychiatric and Mental Health Nursing 2013; 20: 23-34.

25. Happell B, Rushworth L. Can educational methods influence the popularity of psychiatric nursing? Nurse Education Today 2000; 20: 26-318.

26. Corrigan PW, Watson AC. The paradox of selfstigma and mental illness. Clinical Psychology: Science and Practice 2002; 9:35-53. 